ity and environment. At least we may expect a flood of new light on the subject from histometrical investigations, and if the conclusion is different from what the author of the method anticipated it will not at all detract from the credit due him for its development.

BrookLyN, N. Y.

Geo. H. Johnson

\section{METALS ON METALS, WET}

To the Editor of Science: A year or two ago I repeated to a class in elementary physics the statement, familiar to generations of engineers on the authority of General Morin, supported by the approval of Rankine, that the coefficient of friction of metals on metals, wet, is considerably greater than that of metals on metals, dry.

Thereupon a thoughtful youth in the class asked me why, if this were the case, it was customary to put sand on wet car-rails to prevent the slipping of the driving-wheels. Taken aback by this unexpected scepticism, I begged for time to find the right answer to the disturbing question and set to work experimentally on the problem. The student reported after a time that trackmen had told him the water they had trouble with was usually slimy, which seemed to be a fairly satisfactory explanation of the puzzle; but meanwhile my experiments had shown some interesting facts, which I will here set forth.

Using a disk of brass, about $7.5 \mathrm{~cm}$. in diameter and about $0.6 \mathrm{~cm}$. thick, on a flat brass plate, I found:

1. That, when there was no load on the disk, a few small drops of water placed between it and the plate multiplied by a factor which might be as great as 3 the friction between the two.

2. That, when the disk was heavily loaded, the presence of the few small drops of water between it and the plate made little, if any, relative difference in the friction between the two.

3. That when plenty of water was used, so that it covered the whole space beneath the disk and extended somewhat beyond the edge, the disk without load was drawn along the plate quite as easily, apparently, as when both were dry.

From these facts I came to the conclusion that the increase of friction observed in case 1 was not due to an increase in the coefficient of friction caused by the water, but merely to the increase of pressure between the disk and the plate, caused by the suction of the capillary perimeters of the water-spots between them. When there is much water, its perimeter is outside the edge of the disk, is wide, or thick, and has little effect.

Some little search in books dealing with the subject of friction has failed to show there any recognition of this possible explanation, and refutation, of the Morin-Rankine statement of the large value of the coefficient for metals on metals, wet; but I should hardly have written you about the matter if I had not recently found this statement repeated in the "Smithsonian Physical Tables" published in 1903. I hope the new edition of these tables will not quote Rankine on this particular without further evidence.

Edwin H. HaLL

CAMBRIDGe, Mass., April 29, 1911

\section{SCIENTIFIC BOOKS}

The Stability of Truth. By David Starr JoRDan. New York, Henry Holt \& Co. 1911. Pp. 180.

"This little book," says the author, " represents the substance of a course of lectures delivered on the John Calvin McNair foundation in the University of North Carolina, January, 1910."

The chapter headings are: Reality and Science, Reality and the Conduct of Life, Reality and Monoism, Reality and Illusion, Reality and Education, Reality and Tradition.

Evidently something has happened in philosophy, in science or in both when a scientist of the first class, not to say the author of this volume in particular, puts out a book with the good old philosophical term, "Reality" at the head of every chapter. Doubtless in the minds of most scientists there will be little question about where "something has happened." 